\title{
Digital Approach for Measuring Tree Diameters in the Amazon Forest
}

\author{
Carlos Henrique Souza Celes ${ }^{1}$ (D), Raquel Fernandes de Araujo ${ }^{1}$ (D), \\ Fabiano Emmert ${ }^{1}$ (D), Adriano José Nogueira Lima ${ }^{1}$ (D), \\ Moacir Alberto Assis Campos ${ }^{1}$ \\ ${ }^{1}$ Instituto Nacional de Pesquisas da Amazônia - INPA, Ministério da Ciência, Tecnologia, Inovações e \\ Comunicação - MCTIC, Manaus/AM, Brasil.
}

\begin{abstract}
Buttresses and other natural structures modify the shape of stems in Amazonia and change the diameter at breast height (DBH) measured at $1.3 \mathrm{~m}$ at ground level. The lack of adequate measurement techniques affects negatively forest dynamics analyses and biomass estimating. The study evaluated an indirect method of measuring diameters in trees with DBH $>40 \mathrm{~cm}$ using principles of digital photogrammetry. The results obtained with two cameras (smartphone and Sony) were compared with direct measurements using diametric tape and a ladder. The technique is adequate to measure the diameters of trees with measurement point above $2 \mathrm{~m}$ of ground, with a confidence interval of $\pm 1 \mathrm{~cm}$. The use of photogrammetry as a supplementary tool to the diametric tape (IC $\pm 0.24 \mathrm{~cm}$ ) is recommended, helping to measure trees with diameter above the reach of the technician in forest inventories.
\end{abstract}

Keywords: dendrometry, diameter at breast height, forest dynamics, biomass estimation, uncertainty. 


\section{INTRODUCTION}

The measurement of the diameter at breast height (DBH) of tropical forest trees is altered when the stems present natural irregularities, such as tabular roots (Crook et al., 1997; Chapman et al., 1998). The diameter measuring point (DMP) should be moved upwards until it geometrically represents the shape of the stem (Alder \& Synnott, 1992; Amaral et al., 1998; Laar \& Akça, 2007; West, 2009; Ngomanda et al., 2012). In some situations, the displaced DMPs may be inaccessible to direct measurement rather than to the height of the tabular roots, leaving the field personnel to measure them or determine the diameter visually.

The natural irregularities are caused by transverse and longitudinal asymmetrical extensions in the trunk, composed of woody material, formed by aerial and tabular roots, fissured and dehiscent shells, furrows, protrusions and scars (Synnott, 1979; Amaral et al., 1998). The tabular roots or sapopemas, with anchoring function and stabilization of the asymmetric loads suffered during the life of the trees (Crook et al., 1997; Chapman et al., 1998) are frequently the most important for the measurement effect of DBH, (Clark \& Clark, 2000; Clark, 2002; Metcalf et al., 2009). Studies have shown that about $25 \%$ of the trees presented tabular roots, occurring more frequently in the trees of the larger diametric and emergent class. The deformation in the stem caused by the tabular roots reaches up to 12 meters in height and extends laterally by more than 2 meters (Richards, 1936; Warren et al., 1988; Young \& Perkocha, 1994; Crook et al., 1997; Higuchi et al., 1998; Wittmann \& Parolin, 2005).

The stem diameter is estimated subjectively when tabular roots or other irregularities affect the $\mathrm{DBH}$ making DMP inaccessible. Measures of this nature generate discrepant values in the true size of the trees. Statistical analyzes that use overestimated diameters as an explanatory variable are much more influenced by high values, mainly because they are represented naturally by the minority of trees (Lamprecht, 1990). The differences in the values of the data and the diametric distribution interfe negatively in the inferences about the forest dynamics and increase uncertainties of the estimates of biomass and carbon stock (Brown, 1997; Clark \& Clark, 2000; Silva, 2007; Metcalf et al., 2009; West, 2009). The difficulty to access and perform direct measurement displaced in display can be overcome with the use of a ladder, but this equipment is not always used in practice because of the difficulty of getting out to the forest and especially inside of it. In addition, the DMP may still be inaccessible, even with the use of a ladder. In such circumstances, indirect measurement methods are required so - the diameters are measured to any DMP with known accuracy.

The indirect method of forest measurement determines measures without physical contact with the trees. Statistical techniques, mathematics, and optical methods are used to acquire precise measurements (Freitas \& Wichert, 1998; Alder \& Synnott, 1992). Wheeler's pentaprism and Bitterlich's relascope and/or stand-level forest measurement are examples of indirect measurement equipment developed for individual (Alder \& Synnott, 1992; Laar \& Akça, 2007). Photogrammetry techniques are also used as indirect methods and are based on optical and mathematical principles to generate reliable measurements from the photographic record (Wolf, 1983), having wide application in topographic aero-surveys and in forest measurement (Clark et al., 1998; Dean, 2003). Technological advances provided the development of digital photogrammetry to obtain accurate measurements and recognition of real-world objects with a high level of detail and in three dimensions (Wolf, 1983; Brito, 2007). Digital cameras and smartphones, which are commonplace and inexpensive, can be used as digital photogrammetry equipment.

In this context, the objective of this work was to establish a photogrammetry method that uses common digital cameras to measure tree diameters and calculate the errors by comparison with diametric tape measurements. The method was applied in trees with DMP above $2 \mathrm{~m}$, with the use of ladders for measurements with tape. Field procedures and method errors were evaluated to determine the field effectiveness and influence on the forest growth monitoring period.

\section{MATERIAL AND METHODS}

\subsection{Characterization of the study area}

The study was carried out in a permanent plot with $100 \times 100 \mathrm{~m}$ dimensions of the Bionte project, coordinates W $60^{\circ} 09^{\prime} 31.21^{\prime \prime}, \mathrm{S} 2^{\circ} 28^{\prime} 28.82^{\prime \prime}$, located at Experimental Station of Tropical Forestry/ZF-2, Manaus, 
Brazil (Figure 1). The vegetation was characterized by dense ombrophilous forest (IBGE, 2012), and the dominant families were Sapotaceae, Lecythidaceae, Leguminosae, and Burseraceae.Dinizia excelsa Ducke (angelim-pedra), Eschweilera coriaceae (DC.) SA Mori (matá-matá), Protium apiculatum Swartz (breu vemelho) is dominant among the species found in this study (Higuchi et al., 2004; Ter Steege et al., 2013).

\subsection{Data collect}

The data collection comprised the direct and indirect measurement of the diameter of the trees contained in the B1T0 control plot, in which there was no forest exploitation. The trees in this plot are monitored for more than 28 years and their DMPs are marked with red paint. The diameter measurements of both techniques were guided by these markings. The 400 meters of trail were traversed to collect the diameter of 60 trees with $\mathrm{DBH} \geq \sim 40 \mathrm{~cm}$, measured by direct and indirect methods on two occasions. On the first occasion, 35 trees were measured with diametric tape and smartphone and on the second occasion 25 trees were measured with tape and Sony camera. Of them, 13 trees were measured with both cameras.

In the direct method, diametric tape with $0.1 \mathrm{~cm}$ precision was used. A 3-meter aluminum ladder was used to measure the diameter of 11 trees on the first occasion and 7 trees on the second occasion to reach the inaccessible DMPs above two meters height. In the indirect method, a digital camera and a digital laser tape were used to record the distance from the camera to the DMP, important for calculating the diameter. On the first occasion, the camera of a model $4 \mathrm{~S}$ smartphone iPhone was used, with focal length of $4 \mathrm{~mm}$ and resolution of 8 megapixels, called IP4S. On the second occasion, the Sony brand CYBER-SHOT model DSC_HX7 was used, with a focal length of $35 \mathrm{~mm}$ and a resolution of 16.8 megapixels. In this study, it was called SHX7. The laser system used was the Trupulse model 360B, called TDL. The cameras and TDL were coupled with the aid of fasteners.

In the indirect measurement, the responsible collector searches for a position where the target to the DMP is representative at the time of the red marking and that is clear of obstacles, enabling to easily visualize the edge of the tree. Sometimes, it was necessary to clean the viewing area. In the correct position, the distance measurement with the TDL is recorded and a DMP photo is recorded in the center of the picture in a portrait position, with the two digital cameras (SHX7 and IP4S). The tree code, the diameter of the diametric tape, the code of the photograph and the linear distance between the camera and the DMP (with TDL) on both occasions were noted in an appropriate form.

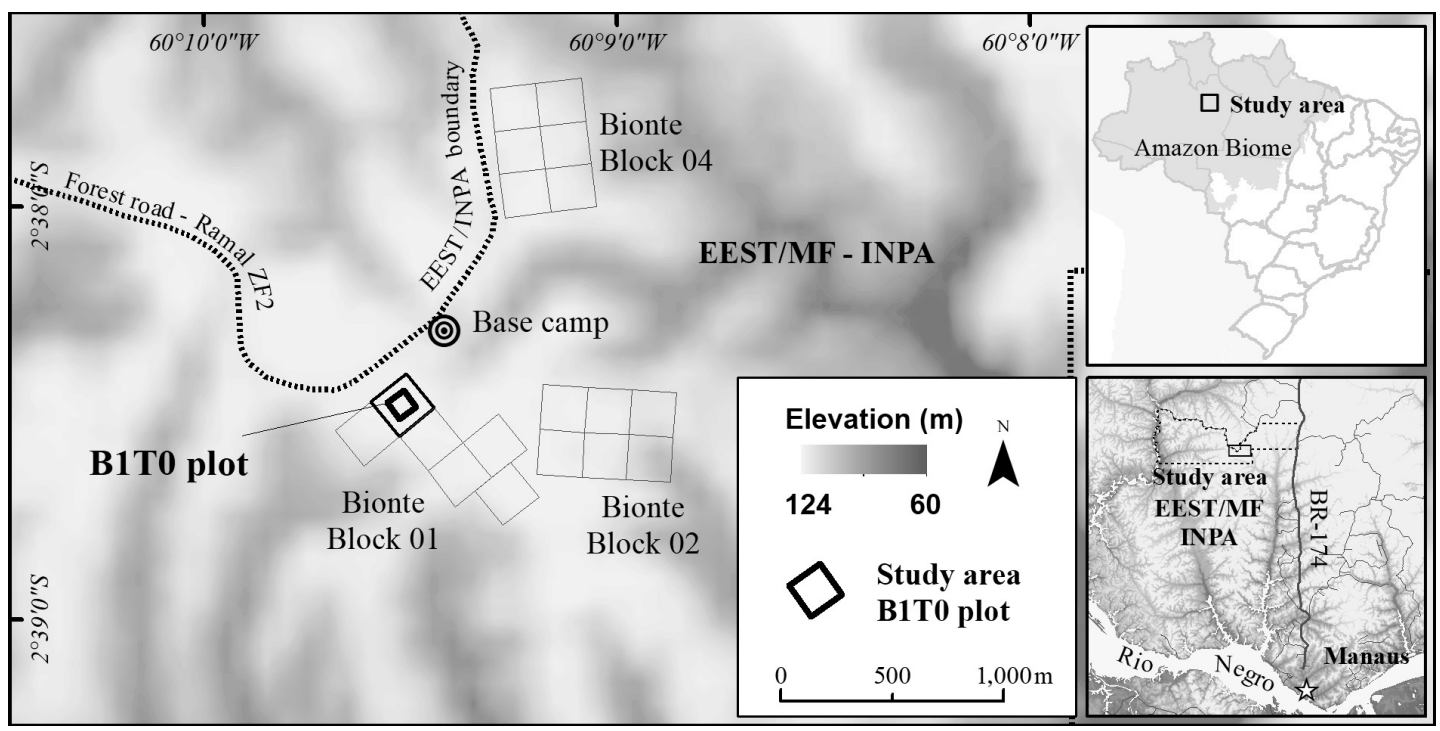

Figure 1. Location of B1T0 study plot at EEST/INPA, Manaus, AM, Brazil. 


\subsection{Calibration of cameras}

Calibration of digital cameras was necessary for the correct calculation of the Instance Field of View (IFOV), which is directly related to the focal length and the amount of megapixels of the camera sensor. Calibration was done in the laboratory for more accurate IFOV calculation. A TDL and a whiteboard were used with plotted targets with linear dimensions (D) of 30,60 and $90 \mathrm{~cm}$, common for SHX7 and IP4S. For the procedure, photos of the targets were recorded at different distances "d, from 360 and $550 \mathrm{~cm}$ for SHX7 and from 410 and $550 \mathrm{~cm}$ for IP4S (Figure 2A). The photos were uploaded to the computer environment and the digital image file (JPG) file was opened in a common photo preview program Preview app (macOS). The number of "p" pixels that covered exactly each " $D$ " target was counted. From the distance obtained by the TDL and the size of the targets, it was possible to calculate the angle "a" that each target/object occupies in the camera (Figure 2A). With these parameters, it was possible to calculate the IFOV obtained by dividing the angle " $\mathrm{a}$ " by the number of pixels "p" (Equation 1).

$$
\mathrm{IFOV}=\frac{360 \cdot \mathrm{D}}{2 \cdot \pi \cdot \mathrm{d} \cdot \mathrm{p}}
$$

where, $\mathrm{IFOV}=$ pixel aperture angle (degrees); $\mathrm{d}=$ distance between the camera and the target $(\mathrm{cm}) ; \mathrm{p}=$ sum of the number of pixels, and; $\mathrm{D}=$ target size $(\mathrm{cm})$.

\subsection{Data processing}

The digital photos of the trees were opened in the Preview app (macOS) and enlarged to the full framing of the vertical boom limits in the DMP ink marking region. This allowed countingthe amount of pixels on the DMP marking, horizontally (side by side), necessary for the calculation of the diameter. The diameter for each image was calculated in two ways: a) Diam_I, considering the diameter as a row of pixels in a one-dimensional plane in the image (Figure 2B), according to Equation 2, and; b) Diam_R, considering the tree with two-dimensional or circular
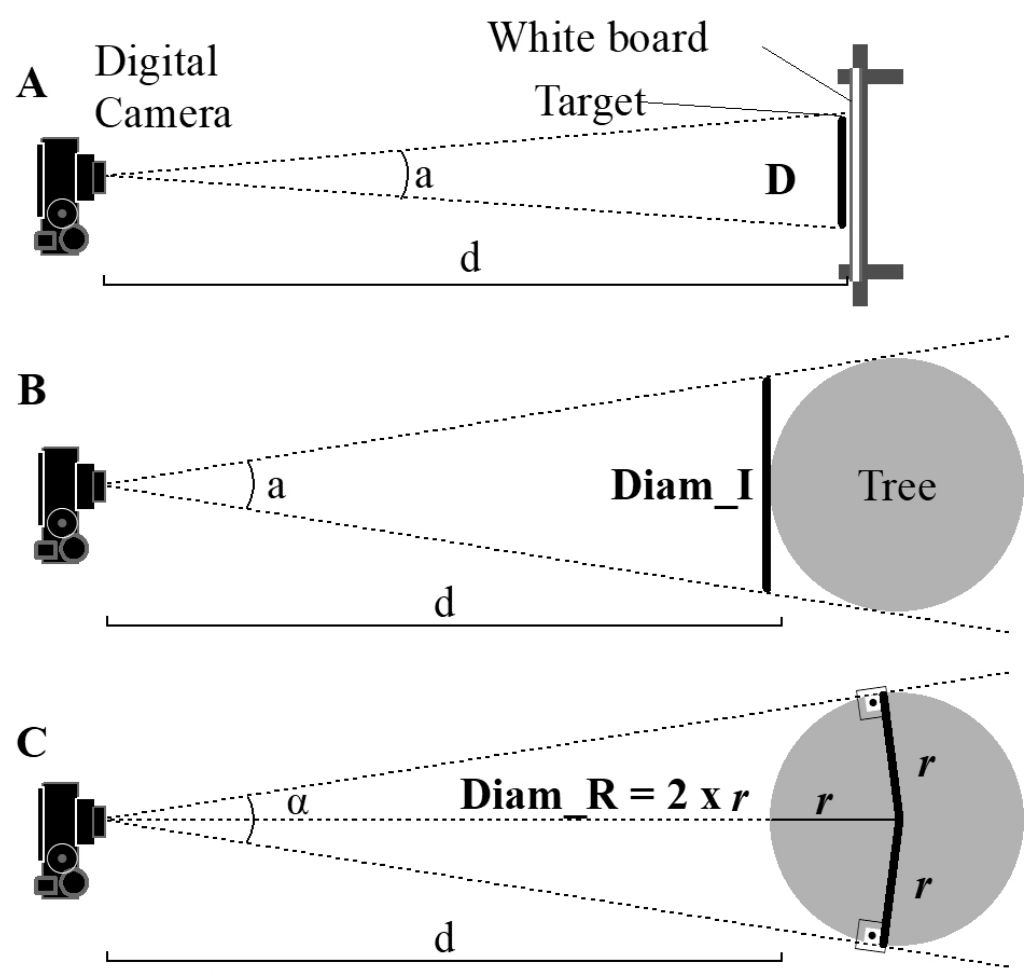

\section{Orthographic view}

Figure 2. (A) Schematic illustration of photographic cameras calibration by IFOV calculation; (B) Schematic illustration of calculation the diameter as a row of pixels in a one-dimensional plane in the image; (C) Schematic illustration of calculation the diameter considering the tree with two-dimensional or circular format. 
format, that is, considering the perspective of image depth (circumferential tangents) to correct the tree diameter (Figure 2C), according to Equations 3 and 4. The indirect measurement process by photogrammetry can be simplified in the scheme of Figure 3.

Diam_I $=\frac{2 . \pi . I F O V \cdot p . d}{360}$

where, Diam_I = diameter at the measuring point $(\mathrm{cm}) ; \mathrm{IFOV}=$ pixel aperture angle (degrees); $\mathrm{p}=$ sum of the number of pixels, and; $d=$ distance between the camera and the tree $(\mathrm{cm})$.

Diam_R $=2 \cdot \frac{\sin \alpha \cdot d}{1-\sin \alpha}$

where, Diam_R = corrected diameter at the measurement point $(\mathrm{cm})$, and; $\alpha=$ corrected angle of view (degrees), obtained according to Equation 4:

$\alpha=\frac{\pi \cdot I F O V \cdot p}{360}$

where, IFOV = pixel aperture angle (degrees); and $\mathrm{p}=$ sum of the number of pixels.

\subsection{Statistical analysis}

All statistical and graphical analyzes were performed in a script in the $\mathrm{R}$ language using RStudio (RStudio Team, 2015). A t-test was performed to verify if the
IFOV calculated for each distance in the calibration was a constant value inherent to the equipment. The $\mathrm{p}$-value of the t-test was used to verify the existence or not of statistical significance in the IFOV value. The averages and uncertainties of the IFOV were calculated for each digital camera and used in the equations Diam_I and Diam_R.

The second analysis verified the existence of differences in the values of diameters obtained by direct and indirect methods. This analysis was based on the assumption that the measurements taken with a diametric tape is more accurate when compared to indirect methods. Thus, the regression analysis was performed having the diameter by the diametrical tape as a dependent variable (observed) and the diameter by photogrammetry as an independent variable (estimated). Trees with inaccessible diameter were selected to analyze the performance of the method in this situation. The trees that were measured on both occasions were also selected for comparison between diameters obtained by the same method. The percentage confidence interval (CI) or uncertainty was calculated at $95 \%$ probability on the mean, evidencing the sample adequacy. Constant or leverage trends were observed in the interpretation of coefficients and graphs. The t-test with paired means was applied to check for differences between tape diameter and photogrammetry. The $\mathrm{p}$-value - of the $\mathrm{t}$-test observed in the graphs was used to interpret the significance of the test.

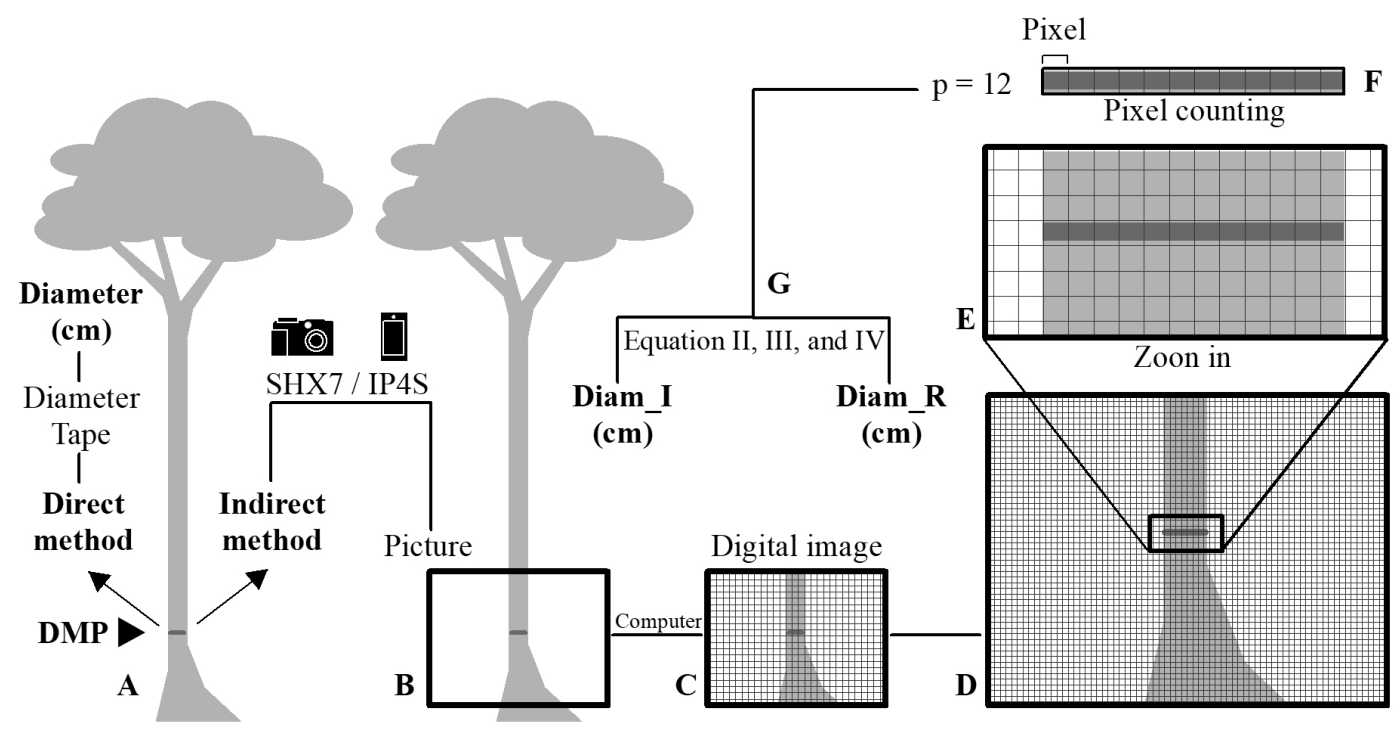

Figure 3. Processing of digital photos for determining tree diameters by indirect method: (A) DMP control; (B) frame of photo taken during fieldwork; (C) digital photo into computer software; (D) enlargement of digital photo; (E) pixel level photo enlargement; (F) DMP pixels accounting; $(\mathrm{G})$ pair diameter determination through 2, 3, and 4 equations. 


\section{RESULTS AND DISCUSSION}

The t-test of the parameters used for the calibration of the cameras (Table 1) was not significant for SHX7 and IP4S, with a p-value of 0.0525 and 0.483 , respectively. Thus, the IFOV averages are representative and inherent to each camera, with a low uncertainty of $\pm 0.10 \%$ or error of $\pm 0.06 \mathrm{~cm}$ in the size of each pixel for SHX7 and of $\pm 0.18 \%$ or the equivalent $\pm 0.11 \mathrm{~cm}$ for IP 4 S. The calibration error was higher for the SHX7 because of a greater difference between the first and second distance measurements performed. For the proposed method, calibration by the IFOV calculation was necessary to prevent systematic errors from being projected in the tree diameters estimates field.

The indirect method for calculating the Diam_I, which considered the tree with one dimension in the photograph, was highly significant by the t-test of paired means (Figure 4). Thus, the projected approximation of the tree diameter in the image presented a marked

Table 1. Results of calibration process for the digital cameras.

\begin{tabular}{|c|c|c|c|c|c|c|c|}
\hline \multicolumn{2}{|c|}{ TARGETS } & \multicolumn{3}{|c|}{ IP4S } & \multicolumn{3}{|c|}{ SHX7 } \\
\hline Id & $\mathrm{D}(\mathrm{cm})$ & $\mathrm{d}(\mathrm{cm})$ & $\mathbf{p}$ & IFOV $\left({ }^{\circ}\right)$ & $\mathrm{d}(\mathrm{cm})$ & $\mathbf{p}$ & IFOV $\left({ }^{\circ}\right)$ \\
\hline 1 & 30 & 410 & 174 & 0.024094 & 360 & 267 & 0.017883 \\
\hline 2 & 60 & 410 & 349 & 0.024025 & 360 & 534 & 0.017883 \\
\hline 3 & 90 & 410 & 523 & 0.024048 & 360 & 802 & 0.017860 \\
\hline 4 & 30 & 550 & 130 & 0.024040 & 550 & 175 & 0.017858 \\
\hline 5 & 60 & 550 & 260 & 0.024040 & 550 & 351 & 0.017808 \\
\hline \multirow[t]{3}{*}{6} & 90 & 550 & 390 & 0.024040 & 550 & 526 & 0.017824 \\
\hline & & & Average & 0.024048 & & Average & 0.017853 \\
\hline & & & Uncertainty & $\pm 0.105 \%$ & & Uncertainty & $\pm 0.181 \%$ \\
\hline
\end{tabular}

IP4S x Diam_I

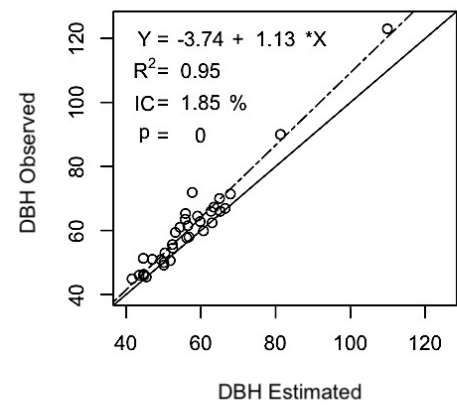

SHX7 x Diam_I

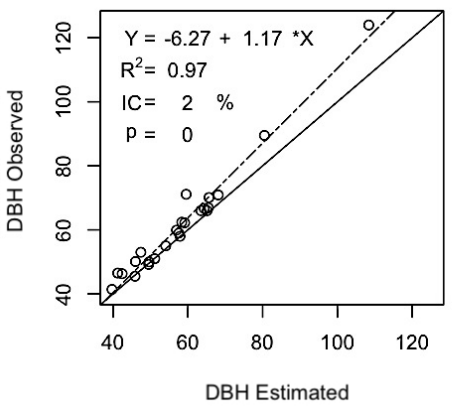

IP4S x Diam_R

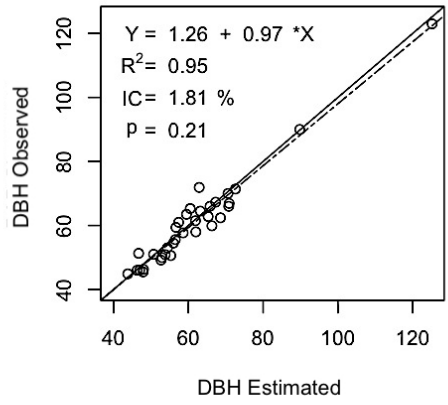

SHX7 x Diam_I

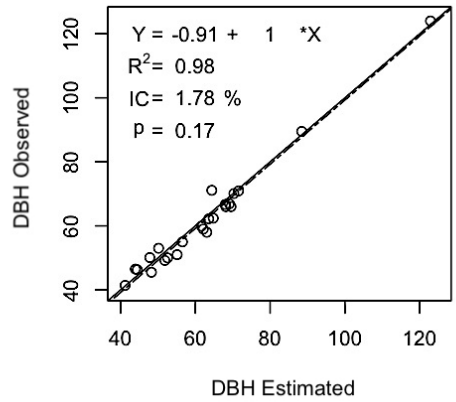

Figure 4. Results of the regression analysis between estimated and observed values of diameter for SHX7 and IP4S by using Diam_I and Diam_R calculations, being $\mathrm{R}^{2}$ the coefficient of determination, IC the confidence interval and $\mathrm{p}$ the probability of the paired t-test. 
tendency of underestimation as the diameter increased. This was observed by the high slope coefficient. Automatic dendrometers, such as CRITERION 400 and RC3H, also underestimated $11 \%$ and $40 \%$, respectively (Nicoletti et al., 2012), showing that the method by calculation of Diam_I, as well as by the dendrometer, was not adequate to estimate the diameter trees.

The indirect method for the calculation of the Diam_R showed a better fit and the t-test was not significant for the two SHX7 and IP4S cameras (Figure 4), and the hypothesis that tape diameters and photogrammetry are similar are not rejected. The method demonstrated consistency with the diameter data taken with the diametric tape, with uncertainty of $\pm 1.8 \%$. The error was $\pm 1 \mathrm{~cm}$ for the diameter of large trees (mean DBH of $\sim 60 \mathrm{~cm}$ ). The difference between the diameter measurements was associated with irregularities of the bole of $46 \%$ of the trees sampled. The three largest residual errors were trees with extremely grooved shafts. In other rainforests, Clark et al. (1998), Gaffrey et al. (2001) and Thiersch (2007) also obtained low standard errors, varying from $3.95 \%$ to $6.9 \%$ by the indirect method with cameras for tree planting of forest plantations. The low errors and the different approaches of each author demonstrate that the technique in digital photogrammetry was efficient also for the developed method.

\section{IP4S}

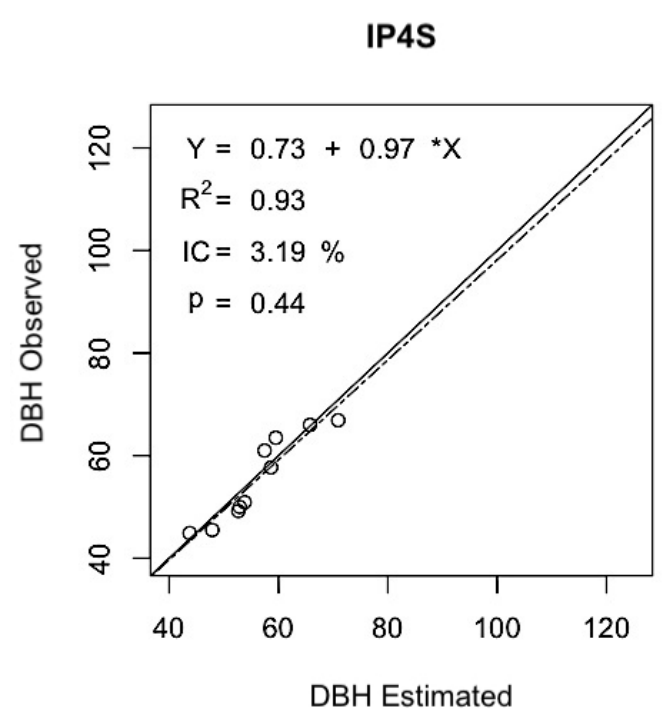

The performance of the two cameras was similar to measure tree diameters. However, the picture quality was lower for the IP4S. Within the forest, the low illumination left $43 \%$ of the dark, unfocused or bumpy IP4S photos. The IP4S is a no longer manufactured device and any latest smartphone already produces high-quality photos in the forest. As for the similarities between SHX7 and IP4S, the automatic adjustment of the contrast between the bottom and the shaft of the trees enabled to visualize the vertical limits of the stem in the photograph, facilitating the counting of the number of pixels, allowing measuring the diameter. The efficiency of two equipment was also maintained for the trees that had their diameter measured over two meters high, that is, with photographs taken at oblique angles.

The direct and indirect methods tested in the study presented good performances when DMP was performed over two meters high, with no tendency and with low uncertainty (Figure 5). The performances of the adjustments were similar to the tests with trees measured in the $\mathrm{DBH}$, although the smaller number of samples favors the elevation of the errors. It is important to note that the distance measurement of the camera - DMP should be taken directly, considering the angle formed by the horizontal axis of the camera's target. If the distance is always taken on the horizontal axis, the diameter value will tend to underestimate.

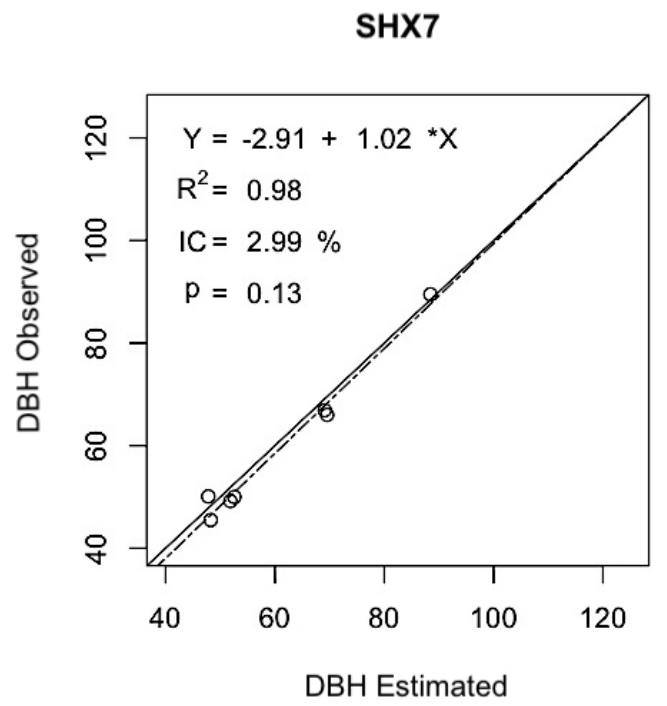

Figure 5. Linear adjustment between the diameters (DMP $>2 \mathrm{~m}$ ) measured by diametric tape (observed) and for SHX7 and IP4S (estimated) by using Diam_R calculation. 
It is recommended for practical use that the distance between the camera and the DMP be taken with the use of TDLs, corroborating with the observations of Gonçalves et al. (2009). The use of optical technologies integrated with laser technologies, as well as GPS, is essential to achieve the practicality, precision, and control of forest inventories and monitoring in the Amazon.

In forest monitoring, tree growth assessment is based on repeated measures of diameter over time. Therefore, the proper accuracy of the measuring equipment to capture the growth of the trees should be close to the value of the increment in diameter of the tree. Considering the errors of the methods (Figure 6 ), $\pm 0.4 \%$ for diametric tape and $2.2 \%$ for photographic cameras and the mean increase in diameter of trees of $1.64 \pm 21 \mathrm{~mm}$ year-1 (Silva et al., 2002), a minimum period of 2 and 8 years would be necessary with the respective methods to capture the growth of the tree with reliability. The performance of repeated measurements with the tape continues to be a method that demonstrates practicality and precision for the monitoring of forest growth. In the case of inventories for biomass stock estimations, the indirect method developed has high applicability, mainly because some trees required indirect methods to guarantee a precise diameter measurement, especially for large trees.

The methods with diametric tape and digital photogrammetry were practical and accurate in the field. Each method requires appropriate situations or that allow the application of procedures correctly. In the present study, 1 individual of the species Dinizia excelsa, popularly known as angelim-pedra, had its diameter measured only by indirect method, with DMP above 5 meters by the presence of a large sapopema. The diameters measured with IP4S and SHX7 were 93.3 and $94.6 \mathrm{~cm}$, respectively. In Table 2, the procedures for measurement by direct and indirect methods were synthesized.

In the direct method, it was observed that the larger the tree, the harder to measure it because it is more difficult to stretch the tape in the transverse perimeter of the tree and position it perpendicular to the shaft. In addition, vines, branches, leaves in the understory and necromasses can hinder access to the tree and serve as a shelter for venomous animals, resulting in risks to workers. In the indirect method by photogrammetry, some obstacles of the sub-forest or vines may not be perceived at the time of the photograph, affecting the later processing of data, mainly in the definition of the limit of the shaft in the images. Excess moisture inside the forest can also cause problems for electronic equipment.

Perhaps the main disadvantage of the proposed method is to have the diameter result measured only in the laboratory or in the office. This requires careful recording of the photographs during the field for later retrieval and processing. In addition, the training of

\section{DAP1 x DAP2}

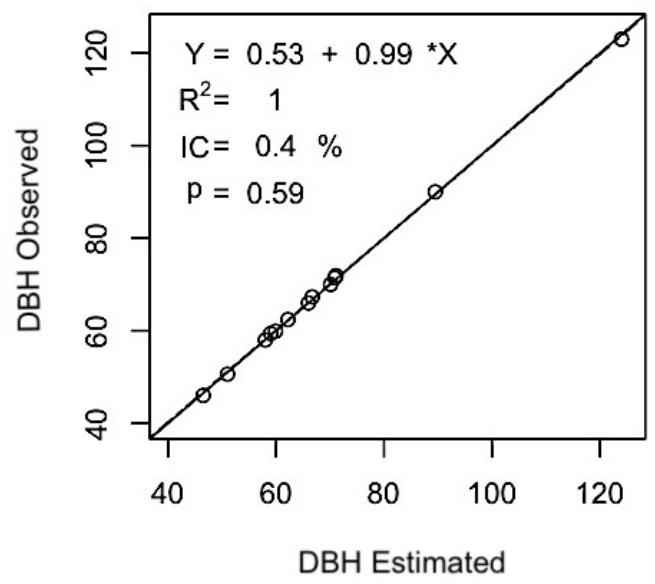

\section{IP4S x SHX7}

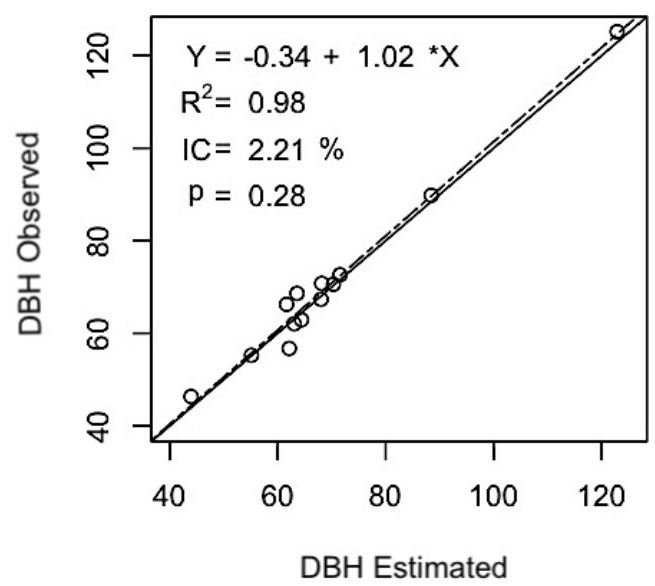

Figure 6. Adjustments between repeated measurements $\left(\mathrm{DBH}_{1} \mathrm{x} \mathrm{DBH}_{2}\right)$ made with diametric tape and adjustments between Diam_R made from SHX7 and IP4S. 
Table 2. Steps for stem diameter measuring by direct and proposed indirect methods.

\begin{tabular}{|c|c|c|}
\hline Step & Diameter Tape & Photogrammetry \\
\hline 1 & Tree view & Tree view \\
\hline 2 & Approach to the tree & Positioning at $\pm 3 \mathrm{~m}$ distance from the tree \\
\hline 3 & Definition of DMP & Definition of DMP and reference points \\
\hline 4 & Verification and cleaning of the shaft surroundings & $\begin{array}{c}\text { Positioning stick/tripod and verification/cleaning } \\
\text { of the visa }\end{array}$ \\
\hline 5 & Hug the tree to pass the tape & Photo record \\
\hline 6 & Positioning of the tape in the perpendicular & $\begin{array}{l}\text { Positioning and measuring the distance with the } \\
\text { laser line. }\end{array}$ \\
\hline 7 & Diameter reading & $\begin{array}{l}\text { In this case, the diameter was obtained in the } \\
\text { laboratory }\end{array}$ \\
\hline
\end{tabular}

field technicians is fundamental to the correct data acquisition procedure. The advantage is the acquisition of digital photography with any camera, just calibrating the camera correctly. The additional idea of testing a smartphone is the possibility of creating a specific program, being a viable alternative to overcome this barrier and obtain the field diameter by photogrammetry and integrate it into the database.

\section{CONCLUSION}

The indirect method by photogrammetry developed is able to measure diameters of large trees in the Amazon, with uncertainty of approximately $\pm 1 \mathrm{~cm}$. The applicability in the field is facilitated with the use of laser tape to measure the distance of the camera to the DMP. The method is simple, practical and can be applied during the forest inventory activities, using it with any low cost digital camera and laser construction. The proposed technique can be applied to subsidize the estimation of the diameter of trees with inaccessible DMP, avoiding the subjectivity of visual estimates or transport of ladders in the field.

\section{ACKNOWLEDGEMENTS}

To the members of the Forest Management Laboratory (LMF-INPA-MCTI) for the logistical, financial and intellectual support and to the projects that helped in the accomplishment of this work. We thank the Coordination for the Improvement of Higher Education Personnel (Capes) and the National Council for Scientific and Technological Development (CNPq) for the grants awarded. To the CADAF project for the equipment used in this study and the INCT/Madeiras da Amazônia for supporting the research.

\section{SUBMISSION STATUS}

Received: 10 dec., 2015

Accepted: 5 oct., 2017

\section{CORRESPONDENCE TO}

\section{Carlos Henrique Souza Celes}

Instituto Nacional de Pesquisas da Amazônia - INPA, Ministério da Ciência, Tecnologia, Inovações e Comunicação - MCTIC, Av. André Araújo, 2936, Petrópolis, CEP 69067-375, Manaus, AM, Brasil

e-mail: carlosceles@yahoo.com.br

\section{FINANCIAL SUPPORT}

Coordenação de Aperfeiçoamento de Pessoal de Nível Superior (Grant/Award Number: 3172/2013).

\section{REFERENCES}

Alder D, Synnott TJ. Permanent sample plot techniques for mixed tropical forest. Oxford: Oxford Forestry Institute; 1992. 124 p.

Amaral P, Veríssimo A, Barreto P, Vidal E. Floresta para sempre: um manual para produção de madeira na Amazônia. Belém: Imazon; 1998.

Brito, JLNS. Fotogrametria digital. Rio de Janeiro: EdUERJ; 2007.

Brown S. Estimating biomass and biomass change of tropical forests: a primer. Rome: FAO; 1997. (FAO Forestry Paper; no. 134).

Chapman CA, Kaufman L, Chapman LJ. Buttress formation and directional tress experienced during critical phases of tree development. Journal of Tropical Ecology 1998; 14(3): 341-349. http://dx.doi.org/10.1017/S0266467498000261. 
Clark DA. Are tropical forests an important carbon sink? Reanalysis of the long-term plot data. Ecological Applications 2002; 12(1): 3-7. http://dx.doi.org/10.1890/10510761(2002)012[0003:ATFAIC]2.0.CO;2.

Clark DB, Clark DA. Landscape-scale variation in forest structure and biomass in a tropical rain forest. Forest Ecology and Management 2000; 137(1-3): 185-198. http:// dx.doi.org/10.1016/S0378-1127(99)00327-8.

Clark N, Wynne RH, Schmoldt DL, Araman PA, Winn MF. Use of a non-metric digital camera for tree stem evaluation. In: Proceedings of the ASPRS/RT Annual Convention; 1998; Tampa, Florida. Bethesda: American Society for Photogrammetry and Remote Sensing; 1998.

Crook MJ, Ennos AR, Banks JR. The function of buttress roots: a comparative study of the anchorage systems of buttressed (Aglaia and Nephelium ramboutan species) and non-buttressed (Mallotus wrayi) tropical trees. Journal of Experimental Botany 1997; 48(314): 1703-1716. http:// dx.doi.org/10.1093/jexbot/48.314.1703.

Dean C. Calculation of wood volume and stem taper using terrestrial single-image close-range photogrammetry and contemporary software tools. Silva Fennica 2003; 37(3): 359-380. http://dx.doi.org/10.14214/sf.495.

Freitas AG, Wichert MXP. Comparação entre instrumentos tradicionais de medição de diâmetro e altura com o criterion 400. Circular Técnica 1998; 188: 1-7.

Gaffrey D, Sloboda B, Fabrika M, Smelko S. Terrestrial single image photogrammetry for measuring standing trees, as applied in the Dobroc virgin forest. Journal of Forest Science 2001; 47: 75-87.

Gonçalves D, Van Eldik T, Pokorny B. O uso de dendrômetro a laser em florestas tropicais: aplicações para o manejo florestal na amazônia. Floresta 2009; 39(1). http://dx.doi. org/10.5380/rf.v39i1.13737.

Higuchi N, Chambers J, Santos J, Ribeiro RJ, Pinto ACM, Silva RP et al. Dinâmica e balanço do carbono da vegetação primaria da Amazônia central. Floresta 2004; 34(3): 295-304. http://dx.doi.org/10.5380/rf.v34i3.2417.

Higuchi N, Santos J, Ribeiro RJ, Minette L, Biot Y. Biomassa da parte aérea da vegetação da floresta tropical úmida de terra-firme da Amazônia brasileira. Acta Amazonica 1998; 28(2): 153-166. http://dx.doi.org/10.1590/180943921998282166.

Instituto Brasileiro de Geografia e Estatística - IBGE. Manual técnico da vegetação brasileira. 2 . ed. Rio de Janeiro: IBGE; 2012.

Laar V, Akça A. Forest mensuration. In: Gadow KV, Pukkala T, Tomé M, editors. Managing forest ecosystems. Dordrecht: Springer; 2007. http://dx.doi.org/10.1007/9781-4020-5991-9.

Lamprecht H. Silvicultura nos trópicos: ecossistemas florestais e respectivas espécies arbóreas: possibilidades e métodos de aproveitamento sustentado. Eschborn: Deutsche GTZ; 1990.
Metcalf CJE, Clark JS, Clark DA. Tree growth inference and prediction when the point of measurement changes: modelling around buttresses in tropical forests. Journal of Tropical Ecology 2009; 25(1): 1-12. http://dx.doi. org/10.1017/S0266467408005646.

Ngomanda A, Mavouroulou QM, Obiang NLE, Iponga DM, Mavoungou JF, Lépengué $\mathrm{N}$ et al. Derivation of diameter measurements for buttressed trees, an example from Gabon. Journal of Tropical Ecology 2012; 28(3): 1-4. http://dx.doi.org/10.1017/S0266467412000144.

Nicoletti MF, Batista JLF, Carvalho SPC, Castro TN. Acurácia de dois dendrômetros ópticos na cubagem não destrutiva para a determinação da biomassa florestal. Pesquisa Florestal Brasileira 2012; 32(70): 139. http:// dx.doi.org/10.4336/2012.pfb.32.70.23.

Richards PW. Ecological observations on the rain forest of Mount Dulit, Sarawak. Part I. Journal of Ecology 1936; 24(1): 1-37. http://dx.doi.org/10.2307/2256268.

RStudio Team. RStudio: integrated development for $R$ [online]. Boston: Rstudio; 2015 [cited 2015 Dec 10]. Available from: http://www.rstudio.com/

Silva RP, Santos J, Tribuzy ES, Chambers JQ, Nakamura $S$, Higuchi N. Diameter increment and growth patterns for individual trees growing in Central Amazon, Brazil. Forest Ecology and Management 2002; 166(1-3): 295-301. http://dx.doi.org/10.1016/S0378-1127(01)00678-8.

Silva RP. Alometria, estoque e dinâmica da biomassa de florestas primárias e secundárias na regiaõ de Manaus (AM) [tese]. Manaus: Universidade Federal do Amazonas; 2007.

Synnott TJ. Tropical Forestry Papers: a manual of permanent plot procedures for tropical rain forests. Oxford: Department of Forestry Commonwealth Forestry Institute, University of Oxford; 1979.

Ter Steege H, Pitman NC, Sabatier D, Baraloto C, Salomão RP, Guevara JE et al. Hyperdominance in the Amazonian tree flora. Science 2013; 342(6156): 1243092. PMid:24136971.

Thiersch CR. Uma nova proposta metodológica para cubagem rigorosa e ajuste de modelos hipsométricos [dissertação]. Lavras: Universidade Federal de Lavras; 2007.

Warren SD, Black HL, Eastmond DA, Whaley WH. W. Whaley WH. Structural function of buttresses of Tachigalia versicolor. Ecology 1988; 69(2): 532-536. http://dx.doi. org/10.2307/1940451.

West PW. Tree and forest measurement. 2 ed. Australia: Southern Cross University Lismor; 2009. http://dx.doi. org/10.1007/978-3-540-95966-3.

Wittmann F, Parolin P. Aboveground roots in Amazonian floodplain trees. Biotropica 2005; 37(4): 609-619. http:// dx.doi.org/10.1111/j.1744-7429.2005.00078.x.

Wolf PR. Elements of photogrammetry. 2. ed. New York: McGraw-Hill; 1983.

Young TP, Perkocha V. Treefalls, crown asymmetry, and buttresses. Journal of Ecology 1994; 82(2): 319-324. http:// dx.doi.org/10.2307/2261299. 